\title{
Reminder about tigers: current status and conservation
}

\begin{abstract}
The tiger (Panthera tigris) is one of the largest cat species. Tigers are carnivorous primal predators, needing large habitats that support their food requirements. At present, there are only approximately 3,890 tigers in the wild, while most tigers (about $10,000)$ are in captivity in zoos, circuses or privately owned. The tiger is a highly endangered species, and it is crucial to find new ways to protect and conserve this amazing animal. In the note, we have outlined the current status of the population, threats and conservation efforts to preserve the species, to inspire the scientific community and stakeholders to protect tigers from total extinction.
\end{abstract}

Keywords: Tiger, panthera tigris, habitat, conservation, threats, poaching, endangered species
Volume 3 Issue 2 - 2018

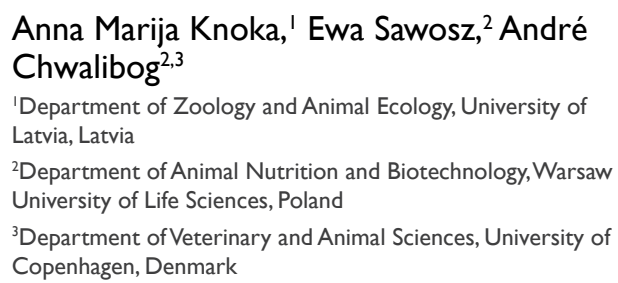

Correspondence: André Chwalibog, University of Copenhagen, Groennegaardsvej 3, 1870 Frederiksberg, Denmark, Tel +4540 9635 73, Email ach@sund.ku.dk

Received: March 08, 2018| Published: March 12, 2018

\section{Introduction}

It is important to understand that tigers play a vital role in the ecosystem, as they are a predator at the top of the food chain: the apex predator. Their scarcity can lead to overpopulation of some types of animals, for example ungulates, and unbalanced growth of flora. For centuries, the tigers have been hunted both as a sport and for their coats, without thinking about the future of these animals. The population of tigers drastically decreased to only about 3,890 tigers in the wild, ${ }^{1}$ hence it is now on the edge of total extinction. In recent years, there has been a desperate surge for new ways to restore tiger populations before these beautiful animals cease to exist. There used to be eleven subspecies of tigers, but due to habitat loss and poaching, there are now only six tiger subspecies. The Trinil and Japanese tigers became extinct in prehistoric times. ${ }^{2}$ In the mid-20th century, the Bali, Caspian and Javan tiger subspecies went extinct. The six remaining subspecies are the Bengal (Panthera tigris), Indochinese (Panthera tigris corbetti) also called Corbett's tiger, Malayan (Panthera tigris jacksoni), Siberian (Panthera tigris altaica) known as Amur tiger, South China (Panthera tigris amoyensis) known as Amoy or Xiamen tiger and Sumatran (Panthera tigris sumatrae) tigers. ${ }^{1,3}$ All living tigers have similar orange-reddish fur (except the white Bengali tiger) with dark stripes, but their sizes and coat patterns differ. The aim of this note is to raise awareness about the diminishing tiger population and to inspire the scientific community to actively protect tigers from total extinction.

\section{Current status}

Tigers can readily adapt to different habitats, for example taigas, savannas, grasslands, tropical forests and evergreen forests. ${ }^{4,5}$ Tigers were historically distributed from the Caucasus and the Caspian Sea to Siberia in the North and Indonesia, and even in Borneo and the
Philippines in the South, populating most of Asia and the Indian subcontinent. However, unfortunately, their distribution range has been reduced dramatically in just one century. ${ }^{5}$ The current situation is that the tiger distribution only includes India, Southeast Asia, Western China and some Russian regions. ${ }^{6}$ The Bengal tiger inhabits parts of India, but it is possible to find some small populations in Bangladesh, Nepal and Bhutan. The Siberian tiger was mainly found in Manchuria by the Amur River. The Amur tiger's habitat is now restricted to the Sikhote-Alin region in the Primorsk and Khabarovsk provinces of the Russian Far East, small pockets in the border areas of China and possibly in North Korea. The South China tiger is native to Southern China, but it is extinct in the wild and now survives only in captivity, for example zoos. The Indochinese tiger is distributed in Southeast China, but it has also been spotted in Burma, Thailand, Vietnam, Cambodia, Laos and Southwest China. The Malayan tiger lives only in the Malay Peninsula. The Sumatran tiger is found in the Indonesian island of Sumatra. ${ }^{7}$ According to a survey from 2010, performed in Bangladesh, Russia, Bhutan, India and Nepal, there were 3,200 tigers in the wild. A more recent survey carried out in 2016 suggested a slightly higher number of 3,890 tigers, but this higher estimate is likely caused by improved survey techniques and is not likely to indicate an increasing population. ${ }^{1}$ Among wild tigers, the Bengal tiger has the largest population, estimated at around 2,500. There are about 500 Malayan tigers and 400-600 Sumatran tigers. There are fewer than 300 Indochinese tigers, and there are about 300 Siberian tigers, while the South China tiger has not been seen in the wild for approximately 20 years. ${ }^{7,8}$

Besides wild tigers, there are approximately 10,000 animals living in captivity globally. ${ }^{9}$ The majority of captive tigers is located in the USA (about 5,000 ) with almost 95\% privately owned. This huge number of captive tigers in the USA and in other countries is due to 
people purchasing cute small cubs, which when grown up are often sold back to breeding farms without any breeding control, hence causing inbreeding and health problems. ${ }^{1}$ One of the greatest threats to the tigers is the spread of farmland and habitat loss. The loss of habitat is due to the growth of the human population destroying the ecosystem. The tigers' primary food is ungulate animals. However, if the habitats of hoofed animals disappear, then the numbers of these animals, thus the number of tigers will diminish as a result. ${ }^{3}$ At present, tigers have lost almost $93 \%$ of their original habitat, and for example, if deforestation continues at a rate of $47 \mathrm{~km}^{2}$ per year, the number of wild animals that tigers prey upon will be significantly reduced, causing a lack of food and consequently reducing the tiger population. ${ }^{1,11}$ Another problem with increasing farmland in areas where tigers dwell is that tigers, which are mainly hungry or sick, occasionally attack domestic livestock. This results in farmers killing the predator of their livestock. ${ }^{7}$ In some places, there have been cases of attacks on humans, and this makes the prejudice towards these cats even worst. ${ }^{1}$

Another major threat to tigers in the wild is poaching. The most valuable part of the tiger is its coat, but many parts of the body are also considered as useful products in traditional Asian medicine. ${ }^{10}$ The poaching affects not only the dead animal but sometimes offspring that still need maternal care. Killed mothers leave their cubs vulnerable to predators and without food. In India alone, about $50 \%$ of tigers' deaths in protected areas are due to poaching. There are indications that poaching has declined, but that it is still common in the Eastern world. It remains a problem that requires an intense and organized effort, but unfortunately, resources are limited. ${ }^{1}$ The tiger population is reducing rapidly, but hunting continues. In Asia, it has been one of the most extravagant sports, and people are willing to pay enormous amounts of money to kill a tiger. Because tigers are hard to find and the hunting is illegal, the hunt is often more exciting for the customers. ${ }^{6}$

\section{Conservation}

With tiger populations in decline, they are disappearing, are on the verge of extinction and must thus be protected. The necessity of protecting this species becomes more urgent as threats to tigers are not decreasing. ${ }^{12}$ the increasing concern about wild tiger survival has prompted several governments in Asia to undertake preliminary measures to try to increase the tiger population and to protect/ develop their habitats. In general, tiger hunting is prohibited, but illegal hunting and poaching still exist. ${ }^{10}$ The trade of tiger products is also a huge problem in spite of governmental policies. Even though there is an increasing policy to educate people to avoid human-tiger conflicts, the capabilities of governments to implement effective educational systems are still very limited. On the other hand, there are international organizations trying to implement some practical conservation measures. ${ }^{1,13}$

There are a few strategies proposed and/or used in tiger conservation. They include monitoring tigers and their pray availability, protecting and developing tiger habitat, eliminating tiger trade and preventing human-tiger conflicts. The basic approach currently in use is monitoring of the tigers and their prey, usually using camera traps, and collecting excrement samples to estimate animal movements and nutritional habits. ${ }^{1}$ Tigers need large living areas, but their habitat has become reduced and several land areas are fragmented. Thus, the solution is to create connections between separated areas. Recently, the World Wildlife Foundation (WWF) started to study how to connect tiger fragmented landscapes by developing "biological corridors" between separated habitats. ${ }^{1}$ The trade of tiger parts and products is a major threat to wild tiger survival.
Together with the global wildlife trade monitoring network TRAFFIC, WWF has tried to create strategies to stop wildlife criminal networks, help governments to shut down black markets and change consumer behaviour. ${ }^{13}$

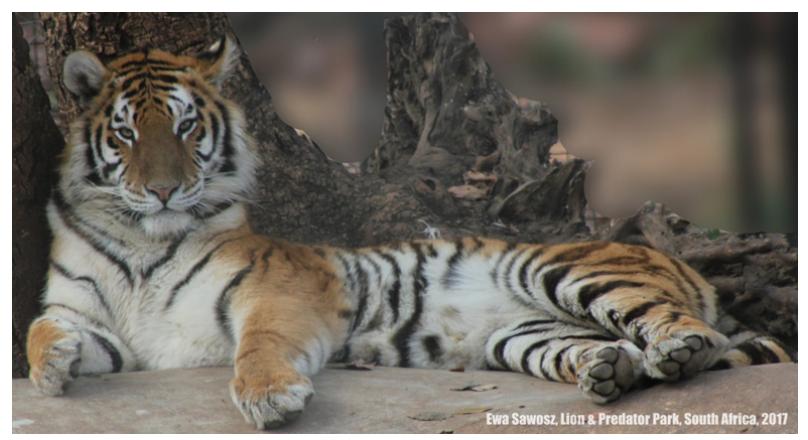

\section{Conclusion}

In this note, we have briefly outlined the present situation of tigers to inspire the scientific community and stakeholders to protect tigers from total extinction. Tigers need large hunting areas and they can adapt to diverse habitats, but they are endangered. Their number is critically small because they are hunted for fur, medical applications, and because of human-animal conflicts. The governmental policies and international conservation strategies are still not sufficient. However, the most important thing is not to lose the hope that in the future these magnificent beings will regain their numbers. Of course, extinct subspecies cannot return, but we must try to save what is still left.

\section{Acknowledgements}

None.

\section{Conflict of interest}

The authors declare no conflict of interest.

\section{References}

1. Tigers. USA: World Wildlife Fund; 2017.

2. Panthera tigris acutidens. USA: Uchytel, Roman; 2012.

3. Panthera tigris. USA: The IUCN Red List of Threatened Species; 2017.

4. Tigers Habitat \& Distribution. USA: SeaWorld Parks \& Entertainment; 2017.

5. Tiger Habitat and Distribution. USA: Bio Expedtion; 2012.

6. Tiger facts and information. Tigers world.

7. Tigers in crisis. USA: Craig Kasnoff; 2018.

8. Tigers. USA: Defenders of Wildlife; 2018.

9. https://www.smithsonianmag.com/

10. Jackson P, Nowell K. Wild Cats Status Survey and Conservation Action Plan. IUCN: 1996.

11. Seidensticker J, Jackson P, Christie S. Riding the Tiger. USA: Tiger Cambridge University Press; 1999.

12. Tilson R, Nyhus PJ. Tigers of the World: The Science, Politics and Conservation of Panthera tigris. USA: Academic Press; 2009.

13. What is CITES. USA: Convention on International Trade in Endangered Species of Wild Fauna and Flora; 2013. 